\title{
ORT.I4 - Prevalence of occult Hepatitis B in patients infected with the hepatitis $C$ will be treated with oral direct acting antivirals
}

Nathália Alves Araujo de Almeida ${ }^{1 *}$; José Junior França de Barrosㄹ Letícia Bomfim Campos; Natália Spitz ${ }^{1}$; Carlos Eduardo Brandão ${ }^{2}$; Catarina Góis de Santana ${ }^{2}$; Vanessa Salete de Paula ${ }^{1}$. 1 Fiocruz - Fundação Oswaldo Cruz; 2Serviço de Gastroenterologia, Hospital Universitário Gaffrée e Guinle - Unirio.

Introduction: Hepatitis B virus (HBV) infection is a worldwide public health problem. The occult hepatites $\mathrm{B}(\mathrm{OBI})$ is determined by the absence of surface antigen (HBsAg) and by the presence of HBV-DNA in the liver or serum of infected patients. The OBI frequency in Brazil is $3.5 \%$ and has great relevance in the clinical context, since it can lead to the development of severe liver disease, such as cirrhosis and hepatocellular carcinoma and even death. Host factors and viral factors of OBI induction may be associated with mutations, especially in S protein and co-infection with other viruses such as the hepatitis $\mathrm{C}$ virus (HCV). According to the Brazilian Clinical Protocol and Therapeutic Guidelines for Hepatitis C and Coinfections (2019), individuals with presence of HBsAg detected prior to the start of use of DAAs need to use $\mathrm{HBV}$ treatment to prevent their reactivation due to treatment of hepatitis $\mathrm{C}$, but in cases where HBsAg is undetected, treatment with DAAs is released without investigation of the presence of HBV-DNA.

Objective: The objective of this study was to estimate the prevalence of individuals who have had previous contact with the HBV and investigate potential cases of OBI in patients chronically infected with HCV (OBI/ HCV) who will undergo treatment with DAAs.

Methodology: The samples of 114 patient prior to the start of treatment with DAAs were selected from a public hospital in Rio de Janeiro. Serum samples were evaluated by enzymelinked immunosorbent assay (EIA) of total $\mathrm{HBc}$ and $\mathrm{HBsAg}$. Anti-HBc-positive and HBsAgnegative samples were tested by real-time PCR (qPCR) and nested-polymerase chain reaction (nested-PCR).

Results: Our results showed that in serological test, 37.71\% (43/114) of the samples were positive to anti-HBc positive and these all were HBsAg negative. HBV DNA positivity with absence of HBsAg, indicating OBI was be found in three (2.58\%) of patients. Neither case developed an ALT and AST flare-up and three patients were anti-HBs positive with viral load detected ranged from 207.14 to 1547 . IU/mL (1.16x103 copies/mL to $8.51 \times 104$ copies $/ \mathrm{mL}$ ). one sample was positive for amplification of the small region by nested-PCR. This difference in molecular tests is expected due to the greater sensitivity of the qPCR technique to detect low viral load. The patient with the highest viral load was positive in amplification by nested-PCR and $\mathrm{HBV}$ was genotype A1, the most prevalent in Brazil.

Conclusion: This is the first study conducted in Brazil whose results are of great relevance to subsidize the data that contribute to the therapeutic guidelines for hepatitis $\mathrm{C}$ and coinfections and to evaluate the cases of OBI/HCV coinfection before the treatments with DAAs.

Keywords: Occult hepatitis B; oral direct acting antivirals; Hepatitis C 